\title{
Further Studies of Copeton Diamonds
}

\author{
H.J. Milledge ${ }^{1}$, F.L.Sutherland ${ }^{2} \&$ P. Kennewell ${ }^{3}$
}

1) Research School of Geological \& Geophysical Sciences, Birkbeck \& University College London, Gower St., London WCIE 6BT, United Kingdom.

2) Mineralogy Section, Australian Museum, 6 College Street, Sydney, NSW, Australia.

3) Cluff Resources Pacific Ltd, Walker Street, North Sydney, NSW, Australia.

An investigation of Copeton diamonds initiated by Henry Meyer (Meyer et. al.,1997) involved the study of 65 diamonds from the Cluff collection in the Australian Museum. These diamonds were selected primarily to obtain data on their inclusion content, and did not involve enough specimens from some sites to make it possible to decide whether or not they represented different populations. It has now been possible to select a further 109 diamonds from the Cluff collection to obtain a more representative sample from the various localities in order to consider this question. Factors influencing the new selection included attention to morphology and surface quality, choice of the smallest specimens representative of any category (since the high nitrogen content of many stones in the original group resulted in infrared (IR) spectra being off-scale), broken stones, and those to which minerals were still attached.

The current totals are as follows:

$\begin{array}{cc}\text { Bingara: } & \text { Eaglehawk. } \\ \text { Monte Cristo. } & 4(1997)+16 \mathrm{New}=22 \\ & 4(1997)+21 \mathrm{New}=25\end{array}$

Copeton: Ryders/Kenzies. $3(1997)+14$ New $=17$

Collas Hill. $\quad 3(1997)+18 \mathrm{New}=21$

Round Mount. $\quad 41(1997)+24$ New $=65$

Mount Ross. $\quad 8(1997)+14 \mathrm{New}=22$

Malacca 2 New $=2 \quad($ TOTAL $=174$ stones)

together with 7 specimens (1997) from other collections, now augmented with 6 (New) Inverell specimens, so that a total of 187 specimens quite well distributed among the different sites are being studied.

\section{Morphology and surface minerals}

Many specimens of both major varieties (yellow, high nitrogen, and white, low nitrogen) show roughly hemispherical depressions or substantial broad rough cracks (Fig. 6 and Fig. 8 of Meyer et al. 1997) which sometimes contain fine-grained minerals, or more substantial lumps, and these are being identified by microprobe analysis. It is often supposed that adhering minerals are of little interest, since they may be late accretions formed long after diamond formation, and may in any case have been altered during the recovery process. However, the fact that depressions and gouges are such frequent feature of the Copeton specimens suggests that they may reveal information about the origin and history of these very unusual diamonds. 
Results of particular interest were obtained from one of the polished plates that had been studied previously, MR6/1 from Mount Ross, and shown to contain coesite. The polished surface cut across a section of the surface gouge, exposing material deep within the crack not previously exposed on the surface. This turned out to be scapolite, a high-pressure mineral which is capable of holding water and $\mathrm{CO}_{2}$, and in this case also contained sulphur. The exposed sections of the gouge also held ilmenite, rutile and $\mathrm{SiO}_{2}$, (still to be checked as quartz or coesite). As many of the diamonds were specifically selected because of the presence of surface minerals, the possibility of a specific mineral assemblage being associated with these specimens.

Stones in the new selection exhibit fractures and cleavages, some of which are old (etched), and many have matt surfaces. No sharp octahedra occur, but many variants with relatively sharp edges approximating to dodecahedra, such as can be produced by laboratory etching (Mendelssohn \& Milledge, 1995a) are found, as well as smooth well-rounded crystals of similar types, confirming that substantial resorption has taken place.

\section{Infrared Spectroscopy}

Infrared transmission spectra have been measured and analysed using the procedures described by Meyer et. al. (1997). All these specimens are rough stones, and the fact that they are rounded and have matt surfaces means that it is difficult to obtain spectra with a straight baseline. In the methods described in Mendelssohn \& Milledge (1995b), the data were baselined within the spreadsheet by the application of a straight-line correction. While this is a satisfactory procedure for parallel-sided polished plates, it cannot always produce a properly base-lined spectrum for rough stones or polished plates with bevels. In order to avoid subjective decisions, all these spectra have been baselined using the automatic correction in the Opus software for comparison with spectra baselined in the spreadsheet.

As in the (1997) set, many spectra were of good quality but off-scale, and the results are being analysed. Nitrogen concentrations range from $<20 \mathrm{ppm}$ to $\sim 2500 \mathrm{ppm}$, and preliminary results show that the nitrogen concentrations and aggregations for the Bingara specimens lie within the ranges shown in Fig. 18 of Meyer et. al (1997). However, the widest range of IR spectra were found in the new Ryders specimens: the lowest concentration $(<20 \mathrm{ppm})$ and one almost fully aggregated specimen in which the platelet peak is absent, and one quite well aggregated specimen without a platelet peak was found in the new Eaglehawk set. No such specimen was found among the complete (1997) selection. The IR results have not yet been correlated with other variables.

\section{References}

Mendelssohn,M.J. \& Milledge, H.J. (1995a) Internat. Geol. Rev. 37, 285-312 ."Morphological charactristics of diamond populations in relation to temperature-dependent growth and dissolution rates".

Mendelssohn, M.J. \& Milledge, H.J. (1995b). Internat. Geol. Rev. 37. 95-110. "Geologically significant information from routine analysis of the mid-infrared spectra of diamonds."

Meyer, H.O.A.M, Milledge,H.J., Sutherland,F.L. and Kennewell, P. (1997) Russ. Geol \& Geophys. 38,No.2,305331. "Unusual diamonds and unique inclusions from New South Wales, Australia 